\title{
Yenidoğanda Pulmoner Hipertansiyon ve Galen Ven Anevrizması Birlikteliği
}

\section{Coexistence of Pulmonary Hypertension and Galen Vein Aneurysm in Newborns}

\section{Muhammet Bulut ${ }^{1}$ (D), Dilek Küçük Alemdar ${ }^{2}$ (D), Kıvanç Çelikkalkan ${ }^{1}$ (D), Emine $\operatorname{Tekin}^{1}$ (D), Özge Eren $^{3}$ (D),

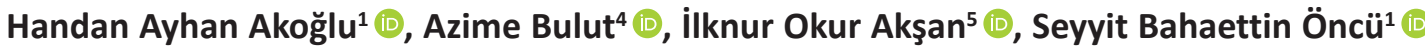

\author{
${ }^{1}$ Giresun University, Medical Faculty, Giresun Gynecology and Child Training and Research Hospital, Department of Pediatrics, Giresun, Turkey \\ ${ }^{2}$ Ordu Univeristy, Faculty of Health Sciences, Department of Pediatric Nursing, Ordu, Turkey \\ ${ }^{3}$ Giresun University, Medical Faculty, Giresun Gynecology and Child Training and Research Hospital, Department of Neonatology, Giresun, Turkey \\ ${ }^{4}$ Giresun University, Medical Faculty, Giresun Training and Research Hospital, Department of Anesthesia and Reanimation, Giresun, Turkey \\ ${ }^{5}$ Giresun University, Medical Faculty, Gynecology and Child Training and Research Hospital, Department of Radiology, Giresun, Turkey
}

ORCID ID: M.B: 0000-0002-5963-1267; D.K.A: 0000-0002-7275-0666; K.Ç: 0000-0002-2619-7177; E.T: 0000-0002-5115-8890; Ö.E: 0000-0002-7809-0654; H.A.A: 0000-0001-9074-8446; A.B: 0000-0001-8164-5617; i.O.A: 0000-0002-4582-9555; S.B.Ö: 0000-0002-6101-8031

Atff/Citation: Bulut M, Kucuk Alemdar D, Celikkalkan K, Tekin E, Eren O, Ayhan Akoglu H, et al. Yenidoğanda pulmoner hipertansiyon ve Galen ven Anevrizması birlikteliği. Çocuk Dergisi - Journal of Child 2021;21(1):26-33. https://doi.org/10.26650/jchild.2021.1.868115

Öz

Amaç: Doğum sonrası süreçte sıklıkla yenidoğan geçici taşipnesi ve konjenital kalp hastalığı ön tanıları nedeniyle geç tanı alabilen ve orta-ağır pulmoner hipertansiyonun eşlik ettiği vakalarda Galen ven anevrizması (GVA) riskine dikkat çekmeyi amaçladık.

Yöntem: GVA tanısıyla merkezimizde takip ve tedavisi yapılan vakalar çalışmaya alındı. Vakaların doğum şekli, doğum haftası, doğum boy-kilo-baş çevresi, yapılan medikal tedaviler ve görüntülemeler hasta dosyasından kaydedildi. Bicetre skoruna göre yapılan risk değerlendirmesi kaydedildi. Bulgular: Vakalarımızın \%80'i kız $(n=4)$ olup, \%80'i $(n=4)$ spontan vajinal yol ile doğurtuldu. Doğum haftaları 39,20 $\pm 0,83$ (min:38, max:40) hafta, ağırlıkları 3488 \pm 415 (min:2820, max:3800) gr, baş çevreleri 36,20 $\pm 1,30$

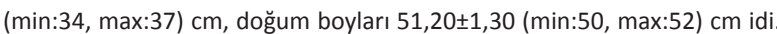
Vakalarımızın tümünün ilk fizik muayenesinde taşipne, inlemeli solunum, siyanoz ve taşikardi mevcut idi. Vakalarımızdan 3'ü entübe edilerek mekanik ventilatör desteği başlanan hastalar olup, 2 tanesi (bebek 4,5) sadece non-invaziv destek aldı. Bicetre skoru düşük olan hasta (bebek 3) erken dönemde tüm tedavilere rağmen stabilleşmedi ve eksitus oldu. Bicetre skoru 12'nin üzerinde olan vakalarımızdan birine (bebek 4) elektif şartlarda cerrahi uygulandı. Tüm vakalarımızda Galen ven anevrizmasına persistan pulmoner hipertansiyon (PPHT) eşlik etti. Vakalarımızdan ikisinde (bebek4-5) hafif-orta, diğer vakalarımızda ağır PHT gelişti. Ağır PPHT'u olan ve inotrop tedaviye rağmen düzelmeyen ve klinik olarak stabilleşmeyen vakalarımız (bebek 1-2) eksitus oldu.

Sonuç: Medikal tedaviye rağmen düzelmeyen PPHT vakalarında çoklu tedavi seçeneklerine başvurmadan, erken aşamada GVA mutlaka akılda tutulmalıdır.

Anahtar Kelimeler: Galen ven anevrizması, kalp yetmezliği, pulmoner hipertansiyon, yenidoğan

\section{ABSTRACT}

Objective: We aimed to consider Galen vein aneurysm(GVA) in cases that may often get a diagnosis later due to the pre-diagnoses of transient tachypnea of newborn and congenital heart disease accompanied by moderate-severe pulmonary hypertension in the postpartum period.

Method: The study included cases that were followed and treated with the diagnosis of GVA in our clinic between 2016-2020. Types of delivery, week of delivery, birthweight/height/head circumference, medical treatments, and imagings were recorded from patient files. The risk evaluation was performed according to Bicetre and the scoring was recorded.

Results: Of our cases; $80 \%(n=4)$ were female, and $80 \%(n=4)$ had been delivered via spontaneous vaginally. Their week of delivery was $39.20 \pm .83$ ( $\min : 38$, max:40), birth weight was $3488 \pm 415 \mathrm{gr}$, head circumference was $36.20 \pm 1.30$ and height was $51.20 \pm 1.30 \mathrm{~cm}$. Firstly, all cases had tachypnea, dyspnea, cyanosis, and tachycardia. Of our cases, three were intubated, others (4.5) received non-invasive support only. The patient (infant 3) with a lower Bicetre score did not stabilize and died. One of our cases (infant 4) whose Bicetre score was above 12 , was operated electively. In all cases the GVA was accompanied by persistent pulmonary hypertension (PPHT). The cases that had severe PPHT and did not improve despite inotrop treatment died.

Conclusion: Galen vein aneurysms should certainly be considered in PPHT cases in the early stage of those that don't respond to multiple treatment options.

Keywords: Galen vein aneurysm, heart failure, newborn, pulmonary hypertension

Sorumlu Yazar/Corresponding Author: Muhammet Bulut E-mail: muhammetbulut023@gmail.com

Başvuru/Submitted: 26.01.2020 • Revizyon Talebi/Revision Requested: 10.02.2021 • Son Revizyon/Last Revision Received: 12.02 .2021 •

Kabul/Accepted: 20.02.2021・ Online Yayın/Published Online: 02.04.2021 


\section{GíRiş}

Yenidoğan döneminde görülen malformasyonları hekim iyi tanıyabilmeli ve en kısa sürede tanı koyabilmelidir. Orta hatta oluşan arteriovenöz malformasyonlar grubunda bulunan Galen ven anevrizması (GVA) intrakraniyal vasküler malformasyonların \%1'inden azını oluştururlar. Görülme sıklığı 1:25000'dir ve erkek cinsiyette daha sık görülür (1). GVA'da en sık olarak sorumlu olan mekanizma internal karotis arterden bu vene bağlanan fistülöz şantlardır (2). Yenidoğan döneminde en sık bulgu veren serebrovasküler patoloji olan GVA, hidrosefali ve kalp yetmezliği ile bulgu verir ve sıklıkla yüksek mortalite ve morbidite ile sonuçlanır (3). Santral sinir sisteminin en büyük toplar damarlarından biri olan Galen Veni (Vena Serebri Magna)'ne ait GVA'nın genişliği, direkt olarak kalp yetmezliğinin şiddeti ile orantılıdır $(2,3)$. Prenatal olarak tanı, genelde üçüncü trimesterde yapılan renkli doppler ultrasonografi ile orta hatta 3.ventrikül arkasında kalan alanda anevrizmatik oluşumun görülüp, hipoekojenik yapılar içinde, venöz ve arteriyel türbülan akımın gösterilmesi ile konulur. Ancak GVA kesin tanısı için fetal MR yapılmalıdır (4) . Tedavide özellikle yenidoğan döneminde tanı alan vakalarda, günümüzde yaygın kullanılan erken embolizasyon yöntemi ile serebral kan akımının azaltılması sağlanarak oluşabilecek komplikasyonlar ve mortalite önemli ölçüde azaltılabilmiştir (5).

Yenidoğan döneminde görülen persistan pulmoner hipertansiyon (PPHT), özellikle term ya da geç pretermlerde, doğum sonrası beklenen pulmoner vasküler basıncın düşmeyip aksine yüksek kalması ile siyanoza neden olan hipoksik solunum yetmezliği durumudur $(6,7)$. PPHT sıklığı 10000 canlı doğumda 2 ile 7 arasında değişmektedir (8,9). PPHT patofizyolojisinde intrauterin ya da postnatal dönemde vasküler yeniden yapılanmada değişiklik, pulmoner vasküler reaktivitede değişim ve vasküler gelişimde meydana gelen bozulmalar rol oynar. Ortalama pulmoner arter basıncı temelde pulmoner vasküler direnç, pulmoner kan akımı ve pulmoner kapiller wedge basıncı faktörlerinden oluşsa da , bu üç faktöre etki eden her şeyden etkilenir (10). PPHT, bir akciğer hastalığına bağlı gelişmediği sürece solunum sıkıntısı genelde hafif görülür (11). Tedavide amaç, pulmoner vasküler yapıların gevşetilmesi ve miyokardiyal disfonksiyon ile periferik vasküler anormalliklerin düzeltilmesidir. PPHT'da miyokardiyal sağ ventrikül hipertrofisi çok arttı̆ında ya da sol ventrikül ön yükü ileri derecede azaldığında sistemik kan akımının sağlanabilmesi için patent duktus arteriyozusa (PDA) ihtiyaç duyulur (9).

GVA özelikle yenidoğan döneminde pulmoner kan akımını arttrarak pulmoner arter basınç artışı, yüksek debili kalp yetmezliği, hidrosefali ve konvülziyonlarla bulgu verir (12). Daha hafif formlarına da süt çocukluğu döneminde en sık 6-11.aylarda baş çevresi artışı ile tanı konulur $(1,2)$.

Yüksek debili kalp yetmezliği, PPHT ve GVA olan vakalarla nadiren karşılaşsak da, bu vakalar komplike malformasyonları nedeni ile hızlı tanı konulmalı ve hızla destek tedavisi vermemiz gereken vakalardır $(13,14)$.

Antenatal tanısı olmayan, erken aşamada yenidoğan geçici taşipnesi ve konjenital kalp hastalığı ön tanılarını alan, primer kalp anomalisi nedenli olmayan kalp yetersizliği ve orta-ağır pulmoner hipertansiyonun eşlik ettiği vakalarda galen ven anevrizmasını hatırlatmak amacıyla hastalarımızı sunuyoruz.

\section{GEREÇ VE YÖNTEM}

Giresun Kadın Doğum ve Çocuk Hastalıkları Eğitim ve Araştırma Hastanesi Yenidoğan Yoğun Bakım Ünitesi'nde 2016-2020 yılları arasında GVA tanısıyla takip ve tedavisi yapılan vakalar çalışmaya alındı. Vakaların doğum haftası, şekli, doğum boy-kilo-baş çevresi ölçümleri, klinik bulguları, yapılan medikal tedaviler, ekokardiyografi ( EKO) ve görüntüleme (kranial ultrasonografi, MRG) raporları/sonuçları hasta dosyasından kaydedildi. PPHT şiddeti; tekrarlayan EKO incelemelerine göre sağ ventrikül basıncının sistemik basınca oranı, ventriküler fonksiyonların değerlendirilmesi ve klinik tablosuna göre yapıldı $(15,16)$ (Tablo 1$)$.

Tablo 1: PPHN Sınıflamasında Klinik ve EKO bulguları (16).

\begin{tabular}{|c|c|c|c|}
\hline PPHN Şiddeti & Hafif & Orta & Ağır \\
\hline - Klinik & $\begin{array}{l}\text {-Artmış solunum iş yükü } \\
\text {-Yüksek FiO2 } \\
\text {-Normal uç-organ fonksiyonları }\end{array}$ & $\begin{array}{l}\text { Hafif pre/post duktal SpO2 farkı } \\
\text { (\%5-10) Azalmış Sistolik Kan Basıncı } \\
\text { Normal / } \downarrow \text { uç-organ fonksiyonları }\end{array}$ & $\begin{array}{l}\text { Pre/post duktal SpO2 farkı } \% 10 \\
\text { Azalmış Sistolik ve diastolik KB } \\
\text { Şok Tablosu (个laktat, asidoz...) }\end{array}$ \\
\hline
\end{tabular}

- Ekokardiyografi Bulguları

Sağ Ventrikül Basıncı

Interventriküler septum

Patent DuctusArteriosus

Patent Foramen Ovale

Sol ventrikül

Sağ ventrikül
Sistemik basıncın $1 / 2$ ile $3 / 4$ 'ü

Düzleşmiş

Çift yönlü

Çift yönlü (Sol sağ)

Normal

Normal
> Sistemik basıncın $3 / 4$ ü

Düzleşmiş

Sıklıkla sağdan sola

Çift yönlü

-Azalmış önyük

-Azalmış/Normal Sol ventrikül output \pm Azalmış fonksiyon

-Azalmış pulmoner kan akımı (Azalmış Sağ ventr. output) -Azalmış Sağ ventr. fonksiyonu -Minimal dilatasyon
Suprasistemik

Paradoksal (Sola doğru)

Sağdan sola

Sağdan sola

-Azalmış önyük

-Azalmış sol ventrikül output

-Azalmış fonksiyon

-Pulmoner kan akımı ileri düzeyde azalmış

(Azalmış Sağ ventr. output)

-Azalmış Sağ ventr. fonksiyonu

-Orta-ağır dilatasyon 
Tablo 2: Bicetre Skorlaması (20).

\begin{tabular}{|c|c|c|c|c|c|}
\hline Puan & Kalp fonksiyonu & Serebral Fonksiyon & Solunum fonksiyonu & Karaciğer fonksiyonu & Böbrek fonksiyonu \\
\hline 5 & Normal & Normal & Normal & - & - \\
\hline 4 & $\begin{array}{l}\text { Kardiyak yüklenme var ancak, } \\
\text { medikal tedavi ihtiyacı yok }\end{array}$ & $\begin{array}{l}\text { Subklinik izole EEG } \\
\text { anormalliği }\end{array}$ & Takipne, beslenebilir & - & - \\
\hline 3 & $\begin{array}{l}\text { Kalp yetersizlik-medikal tedavi } \\
\text { ile stabil }\end{array}$ & $\begin{array}{l}\text { Non-konvülzif aralıklı } \\
\text { nörolojik bulgular }\end{array}$ & Takipne, beslenemez & $\begin{array}{l}\text { Hepatomegali yok, } \\
\text { normal fonksiyon }\end{array}$ & Normal \\
\hline 2 & $\begin{array}{l}\text { Kalp yetersizlik -medikal } \\
\text { tedavi ile stabil değil }\end{array}$ & İzole konvülziyon & $\begin{array}{l}\text { Yardımlı ventilasyon, normal } \\
\text { satürasyon } \mathrm{FiO} 2 \%<25\end{array}$ & $\begin{array}{l}\text { Hepatomegali; normal } \\
\text { fonksiyon }\end{array}$ & Geçici anüri \\
\hline 1 & Ventilatör gereksinimi & Nöbet & $\begin{array}{l}\text { Yardımlı ventilasyon, normal } \\
\text { satürasyon } \mathrm{FiO} 2 \%>25\end{array}$ & $\begin{array}{l}\text { Orta veya geçici } \\
\text { karaciğer yetersizliği }\end{array}$ & $\begin{array}{l}\text { Tedavi ile stabil } \\
\text { olmayan diürez }\end{array}$ \\
\hline 0 & $\begin{array}{l}\text { Medikal tedaviye direnç kalp } \\
\text { yetmezliği }\end{array}$ & Kalıcı nörolojik bulgular & $\begin{array}{l}\text { Yardımlı ventilasyon, } \\
\text { desatürasyon }\end{array}$ & $\begin{array}{l}\text { Koagülopati, } \\
\text { enzim yüksekliği }\end{array}$ & Anüri \\
\hline
\end{tabular}

Maksimum skor: 5 (kardiyak)+5 (serebral)+5 (solunum)+3 (Karaciğer) +3 (Böbrek)=21.

Skor $>12=$ Embolizasyon geciktirilebilir; Skor 8-12=Acil embolizasyon; Skor $<8=$ Tedavi yapılmaz

Kranial MR, MR anjiografileri tanı ve tiplendirme nedeniyle tekrar anestezi eşliğinde çekildi. Deneyimli bir nöroradyolog tarafindan GVA sınıflaması yapıldı.

Tüm hastalarımıza tanı konulduktan sonra Bicetre skorlaması yapıldı (Tablo 2). Endovasküler embolizasyon kararı Nöroradyoloji ekibine konsülte edilerek Bicêtre skorlamasına göre belirlendi (20).

Skorlamaya göre embolizasyon endikasyonu olan ve klinik açıdan stabil olan vakalara uygun merkezde anjiyografi ünitesinde sedasyon altında endovasküler embolizasyon yapıldı.

Çalışmamız için Giresun Üniversitesi Klinik Araştırmalar Etik Kurulu Başkanlığı'ndan 06.02.2020/19 onay numarası ile onam alındı. İstatistiksel analiz için SPSS 21 paket programı kullanıldı. Hasta verileri sayı, ortalama, standart sapma, min-max (range) olarak hesaplandı.

\section{BULGULAR}

GVA tanısı konulan toplam 5 hastamızın verileri değerlendirildi. Hastalarımızın \%80'i kız ( $n=4), \% 20$ 'si erkek ( $n=1)$ idi. \%80'i ( $n=4)$ normal spontan vajinal yol ile doğurtuldu. Gestasyonel haftaları $39,20 \pm 0,83$ hafta (38-40) idi. Doğum ağırlıkları, baş çevreleri ve boyları sırasıyla, $3488 \pm 415 \mathrm{gr}$ (2820-3800), 36,20 $\pm 1,30 \mathrm{~cm}$ (3437), $51,20 \pm 1,30$ (50-52) cm idi. Hastaların demografik özellikleri Tablo 3'de verilmiştir.

Antenatal tanısı olan bir hastamız elektif sezaryen ile doğurtularak yakın gözlem, tetkik ve tedavi amaçlı yenidoğan yoğun bakım ünitesine yatırıldı. Diğer hastaların antenatal tanıları yoktu. Bu hastalar postnatal takiplerindeki patolojik fizik muayene bulguları nedeniyle yenidoğan yoğun bakım ünitesine yatırıldı. Hastaların diğer ikisi (\%40) ise yenidoğan geçici takipnesi, siyanoz, beslenememe ve sepsis ön tanılarıyla ileri tetkik ve tedavi amaçı hastanemize sevk edilmişti.

Tüm hastaların ilk fizik muayenesinde ortak bulgu olarak takipne, inlemeli solunum, siyanoz ve taşikardi mevcuttu. Beslenme intoleransı, hipoglisemi ve dolaşım bozukluğu da diğer sık görülen bulgular arasındaydı.
Antenatal tanısı olan ve elektif sezaryen ile doğurtulan bir hastamıza (bebek 3 ) doğum sonrası ağır solunum sıkıntısı nedeniyle endotrakeal entübasyon uygulanarak invaziv mekanik ventilatör desteği verildi. Diğer hastalara (bebek 1 ve 2 ) başlangıçta hafif solunum sıkıntıları olması nedeniyle non-invaziv solunum desteği verilmişti. Ancak takiplerinde solunum sıkıntılarının artması ve kan gazlarında hiperkarbi ve solunumsal asidozlarının belirginlişmesi üzerine entübe edilerek invaziv mekanik ventilasyon desteğine alındı. Toplamda hastaların 3'ü (\%60) invaziv mekanik ventilatör desteği, 2'si (\%40) ise sadece non-invaziv solunum desteği aldı.

Antenatal tanısı olan hastamızın yenidoğan yoğun bakım ünitesine yatth̆ı ilk günden itibaren ağır kalp yetmezliği vardı. Bu nedenle postnatal ilk saatlerden itibaren inotrop desteği, diüretik tedavisi ve sıvı kısıtlaması uygulandı. Diğer hastalara ise mekanik ventilatör desteği altında hemodinamilerinin bozulması ve takiplerinde dolaşım yetersizliği olması üzerine inotrop(dopamin,dobutamin) destek başlanmışt.

Tüm hastalar ampirik antibiyoterapi, diüretik ve sildenafil tedavisi aldı, ayrıca hastalara aldığı-çıkardığı dengesine göre sıvı kısıtlaması da yapıldı. Üç hastada (\%60) kardiyak destek tedavisinin yanında ağır PHT nedeniyle prostoglandin $\mathrm{I}_{2}$ (Ilioprost) tedavileri de verildi.

Galen ven anevrizması tanısı konulan tüm hastalarımıza PHT eşlik etti. íki hastada (\% 40) hafif-orta, diğer hastalarda ise ağır PHT mevcuttu. Hastaların birine (bebek 5) ek olarak galaktozemi tanısı da konularak erken dönemde laktozsuz formüla ve destek tedavileri başlandı. Hafif PHT olan hastamızın (bebek 5) tablosu sildenafil (I 0.5-2 mg/kg/doz günde 6 saatte arayla) ve prostoglandin I (Ilioprost, 1-2.5 $\mathrm{\mu g} / \mathrm{kg} 2-4$ saat arayla, inhale) tedavisi ile geriledi. Hafif-orta derecede pulmoner hipertansiyonu olan diğer hastamızda (bebek 4) ise cerrahi işleme gerek duyulmadı. Her iki hastamız da (bebek 4 ve 5) iyileşerek sırasıyla 47. ve 33. günlerinde taburcu edildi. Bebek 4'e elektif şartlarda (6. ayında) embolizasyon uygulandı. Ağır PHT'si olan ve inotrop desteğe rağmen düzelmeyen ve klinik olarak stabilleşmeyen bebekler (bebek 1,2,3) (\%60) eksitus oldu. Bebeklerimizden eksitus olan (bebek 3 ) vakamız ve cerrahi işlem 
Tablo 3: Galen Ven Anevrizma tanılı hastalarımızın demografik özellikleri.

\begin{tabular}{|c|c|c|c|c|c|c|}
\hline & Bebek 1 & Bebek 2 & Bebek 3 & Bebek 4 & Bebek 5 & $\begin{array}{c}\text { Mean } \pm \\
\text { Standart Sapma }\end{array}$ \\
\hline \multicolumn{7}{|l|}{ Cinsiyet } \\
\hline 1. $K ı z$ & $x$ & $x$ & & $x$ & $x$ & \\
\hline 2. Erkek & & & $x$ & & & \\
\hline \multicolumn{7}{|l|}{ Doğum şekli } \\
\hline 1. NSVY & $x$ & $x$ & & $x$ & $x$ & \\
\hline 2. Sezaryen $(C / S)$ & & & $x$ & & & \\
\hline Doğum haftası & 38 & 40 & 40 & 39 & 39 & $39,20 \pm 0,83$ \\
\hline Doğum kilosu (g) & 2820 & 3350 & 3680 & 3800 & 3790 & $3488 \pm 415$ \\
\hline Doğum boyu $(\mathrm{cm})$ & 52 & 51 & 51 & 52 & 50 & $51,20 \pm 1,30$ \\
\hline Doğum baş çevresi $(\mathrm{cm})$ & 37 & 37 & 37 & 34 & 36 & $36,20 \pm 1,30$ \\
\hline \multicolumn{7}{|l|}{ Yatış tanısı } \\
\hline \multicolumn{7}{|l|}{ Prematürite } \\
\hline RDS & $x$ & & $x$ & & & \\
\hline Yenidoğan geçici takipnesi & & $x$ & & $x$ & $x$ & \\
\hline Kalp yetersizliği & $x$ & $x$ & $x$ & $x$ & $x$ & \\
\hline Pulmoner hipertansiyon & $x$ & $x$ & $x$ & $x$ & $x$ & \\
\hline Beslenme intoleransı & $x$ & & $x$ & & $x$ & \\
\hline Hiperbilirubinemi & $x$ & & $x$ & & $x$ & \\
\hline Metabolikasidoz & $x$ & & $x$ & $x$ & $x$ & \\
\hline Galen ven anevrizması & $x$ & $x$ & $x$ & $x$ & $x$ & \\
\hline Sepsis & $x$ & $x$ & $x$ & $x$ & $x$ & \\
\hline \multicolumn{7}{|l|}{ Semptomlar } \\
\hline Taşipne, inleme & $x$ & $x$ & $x$ & $x$ & $x$ & \\
\hline Siyanoz & $x$ & $x$ & $x$ & $x$ & $x$ & \\
\hline Taşikardi & $x$ & $x$ & $x$ & & $x$ & \\
\hline Beslenememe & & $x$ & $x$ & $x$ & $x$ & \\
\hline Kalpte üfürüm & & $x$ & $x$ & $x$ & & \\
\hline Fontanelde üfürüm & & & $x$ & & & \\
\hline Hepatomegali & & & $x$ & & & \\
\hline Hipoglisemi & $x$ & & & $x$ & $x$ & \\
\hline Dolaşım bozukluğu & & $x$ & $x$ & & $x$ & \\
\hline \multicolumn{7}{|l|}{ Pulmoner hipertansiyon (derecesi) } \\
\hline \multicolumn{7}{|l|}{ Hafif } \\
\hline Orta & & & & $x$ & $x$ & \\
\hline Ağır & $x$ & $x$ & $x$ & & & \\
\hline \multicolumn{7}{|l|}{ Galen ven anevrizması (tipi) } \\
\hline Tip-1 Kolloidal & $x$ & $x$ & $x$ & $x$ & $x$ & \\
\hline \multicolumn{7}{|l|}{ Tip-2 Mural } \\
\hline \multicolumn{7}{|l|}{ Tip-3 Mikst } \\
\hline Tanı konulma günü (gün) & 7 & 17 & 0 & 4 & 23 & $10,20 \pm 9,52$ \\
\hline \multicolumn{7}{|l|}{ Tedavi: PHT \& Galen ven anevrizması } \\
\hline Sıvı kısıtlaması & $x$ & $x$ & $x$ & $x$ & $x$ & \\
\hline Diüretik & $x$ & $x$ & $x$ & $x$ & $x$ & \\
\hline İnotrop & $x$ & $x$ & $x$ & & $x$ & \\
\hline Sildenafil & $x$ & $x$ & $x$ & $x$ & $x$ & \\
\hline Prostoglandin $\mathrm{I}_{2}$ & $x$ & $x$ & $x$ & $x$ & $x$ & \\
\hline Antibiyoterapi & $x$ & $x$ & $x$ & $x$ & $x$ & \\
\hline Entübasyon & $x$ & $x$ & $x$ & & & \\
\hline \multicolumn{7}{|l|}{ Ek tanılar } \\
\hline Primerpulmonerstenoz & $x$ & $x$ & $x$ & & & \\
\hline Sekundum atrial septal defekt & $x$ & $x$ & $x$ & $x$ & $x$ & \\
\hline Patent duktus arteriosus & $x$ & $x$ & $x$ & & & \\
\hline Metabolik asidoz & $x$ & $x$ & $x$ & $x$ & $x$ & \\
\hline Hidrosefali & $x$ & $x$ & & $x$ & & \\
\hline Epilepsi & $x$ & $x$ & $x$ & & $x$ & \\
\hline \multicolumn{7}{|l|}{ Sonuç } \\
\hline Taburcu & & & & X (47.Gün) & X (33.gün) & \\
\hline Endovasküler embolizasyon & & & & $x$ & & \\
\hline Eksitus & $x$ & $x$ & $x$ & & & \\
\hline Bicetre skoru & 9 & 11 & 5 & 14 & 16 & \\
\hline
\end{tabular}




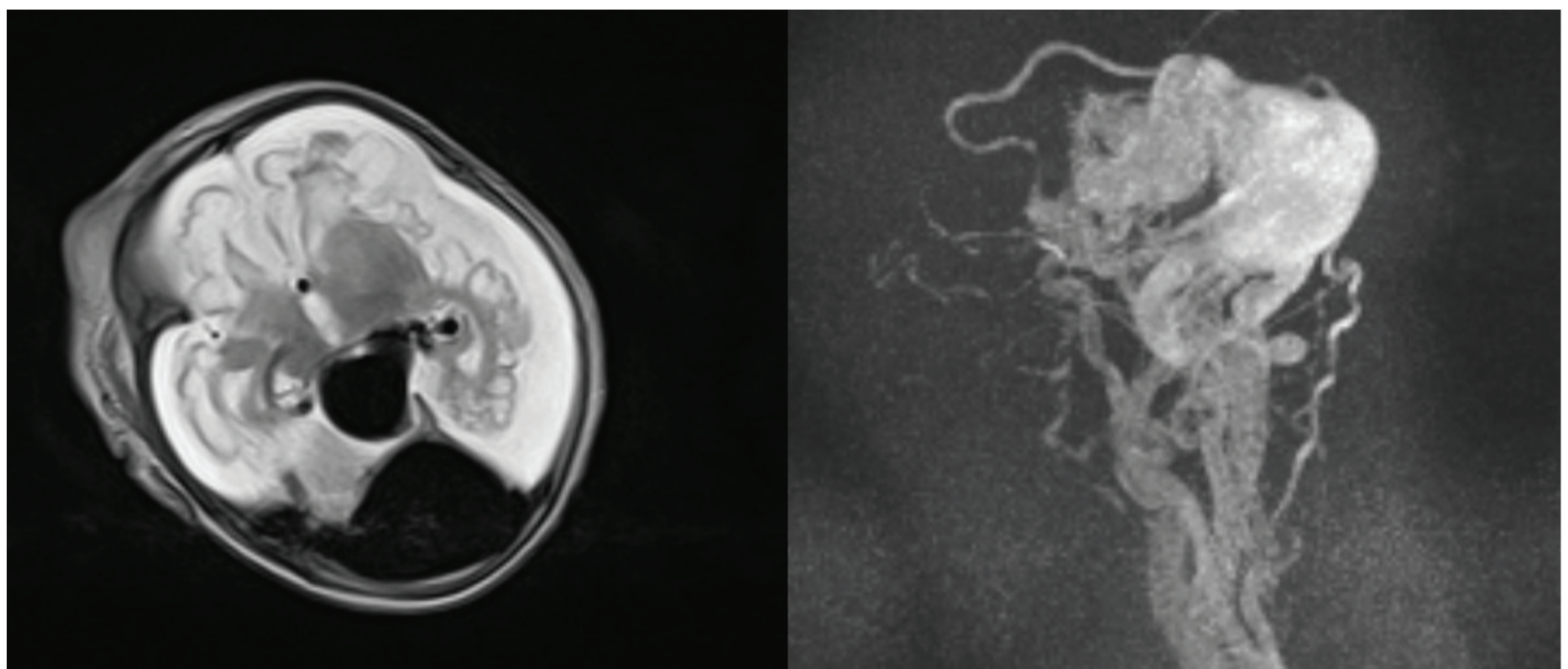

Şekil 1 (Bebek 3): A-T2A aksiyal MR görüntüde Galen ven anevrizması, straight sinüs ve konfluens sinuumda anevrizmatik dilatasyon, beyin parankiminde yaygın kistik değişiklikler. B-MR venografide Galen ven anevrizmasına ait görünüm.

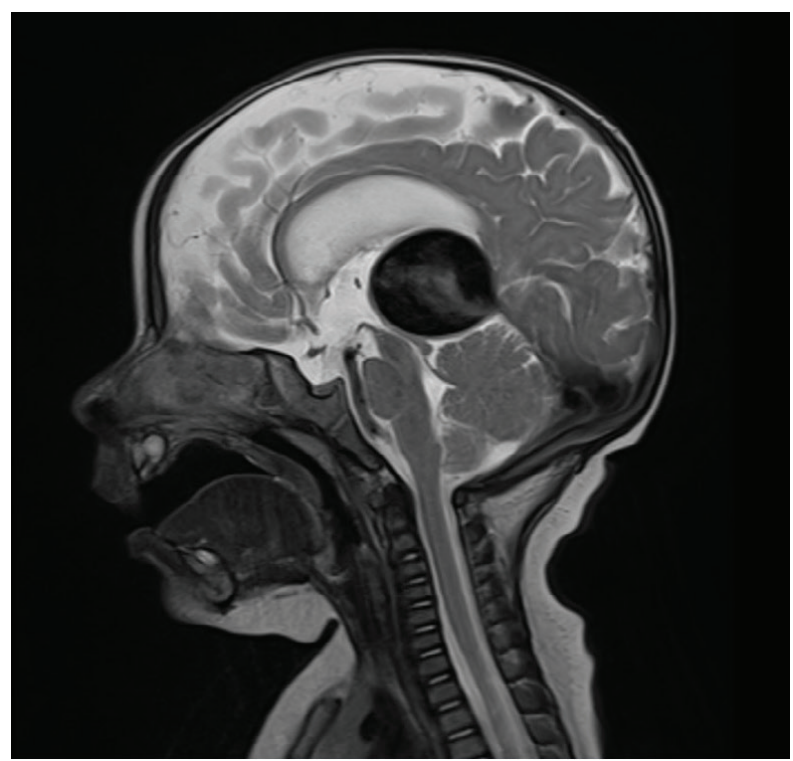

Şekil 2 (Bebek 5): T2A sagittal MR görüntüde anevrizmatik Galen veni ve bası etkisine sekonder lateral ventriküllerde genişleme.

yapılan vakamızın (bebek 4) kranial görüntülemeleri Şekil 1 ve Şekil 2 olarak verildi.

Erken dönemde kalp yetersizliği medikal olarak düzelen hastamız (bebek 5) 34 aylık olup, konuşabilmekle beraber bilişsel ve kognitif fonksiyonlarında hafif geriliği mevcut idi. Hastamız yürüyebilmekte ancak motor gelişimi yaşıtlarının gerisinde devam etmekteydi. Yenidoğan döneminde geçirdiği nöbet sonrası başlanan antikonvülzif tedavisi devam etmekte olup aktif nöbeti yoktur, elektroensefalografisi (EEG) normal olarak takibi devam etmektedir. Kalp yetmezliği tedavisi medikal olarak kontrol altına alınan ancak 6 . ayında endovasküler cerrahi tedavi uygulanan hastamızın (bebek 4) mevcut yaşı 20 ay olup son muayenesinde ciddi düzeyde nöromotor geriliği mevcuttu, konuşmaya ve yürümeye başlamamışt, ancak destekli oturabiliyordu (Denver gelişim testi: Kaba motor, ince motor 10 aylık, dil, kişisel sosyal alan: 7 aylık düzeyinde).

\section{TARTIŞMA}

GVA sıklıkla kötü prognoz ile seyreden vasküler malformasyonlardan olup konjenital intrakraniyal arteriyovenöz şantlardandır. Görülme sıklığı 1/25.000'den daha nadir olup, kraniyal malformasyonların \%1'inden daha azdır $(8,9)$. Derin serebral galen veni üzerinde gelişen arteriyovenöz şantlar anevrizmaya neden olmaktadır.

Internal karotid arter ya da diğer anjiomatöz köprüler vasıtasıyla da galen venine ulaşan fistülöz şantlar bu malformasyona sıklıkla neden olmaktadır $(17,18)$.

GVA klinik olarak ortaya çıktığı yaş gruplarına göre farklı bulgular ile seyredebilir. Yenidoğan döneminde prezente olan vakalarda sıklıkla kalp yetersizliği, pulmoner hipertansiyon ve solunum yetmezliği bulguları ön planda olsa da daha ileri yaşlarda hidrosefali, nörogelişimsel bozukluk ve hafif kardiyomegali vb. bulguları ile de ortaya çıkabilmektedir $(19,25,26)$. Yenidoğan döneminde saptanan vakalar sıklıkla ağır semptomlar ile seyreder ve mortalitesi yüksektir (26-30). Yenidoğan döneminde primer kardiyak kaynaklı olmayan kalp yetmezliği ve pulmoner hipertansiyon nedenleri nadirdir. Daha çok yapısal kalp hastalıklarına ve kardiyopulmoner vasküler yapılardaki anormalliklere sekonder gelişen PHT ön plandadır. Dolayısıyla altta yatan bir kalp veya pulmoner kaynaklı olmayan kalp yetmezliği ve pulmoner hipertansiyonu olan hastalarda mutlaka akla arteriovenöz malformasyonlar gelmelidir. Arteriovenöz malformasyonlar içerisinde erken dönemde yaşamsal fonksiyonları bozan ve kötü prognozu olan anomalilerin başında da GVA gelmektedir. Tanısal açıdan şüphe duyulan vakalarda kraniyal ultrasonografi (USG), MRG ve anjiografi ile tanı doğrulanmalıdır $(20,21)$. 
Lasjaunias ve ark. yaptıkları günümüzde de geçerliliğini koruyan sınıflama daha çok fistüllerin yerleşim yerlerine dayanmakta olup, koroidal ve mural tip olarak ikiye ayrılmaktadır (22). Her ikisinin beraber görülebildiği tipe ise mikst tip adı verilir. Koroidal tip en sık görülen tip olmakla birlikte daha çok erken neonatal dönemde bulgu veren, ağır kalp yetmezliği, ağır PHT ve çoklu organ yetmezliği ile giden tip olup, kuadrigeminal veya koroidal arterler ile median venöz cep arasında direkt arteriyovenöz fistüllerin gelişmesi sonucu oluşur. Mural tip ise daha ileri yaşlarda ortaya çıkan parankimal arteiyovenöz malformasyonlardır. Nidüs daha çok mezensefalon ve talamusdan galen venine boşalarak burada anevrizmal genişlemeye neden olur. Vasküler duvarda fistüller sıklıkla inferior ve lateralde olup, zayıf akımlıdır. Genellikle de semptom vermezler $(23,24)$.

GVA'ların Galen venindeki malformasyonun genişliğine göre oluşturdukları hemodinamik instabilite ve kalp yetmezlik bulguları farklılık göstermiştir. Literatürde, mortalite belirlenirken hastaların seçimi ve dahil edilme kriterleri değişiklik gösterdiğinden mortalite oranları \%20-91 gibi geniş bir aralıktadır (19,2529,32). Ülkemizde Bozkaya ve ark. çalışmasında hastaların \%91'i koroidal tipte olup mortalite oranı \%73 olarak bildirilmiştir (29).

Çalışmamızdaki hastalarımızın hepsi koroidal tipte olup mortalite oranı \%60 ile literatüre benzerlik göstermekteydi. Mortalite oranının yüksek çıkmasında vakalarımızın hemen hepsinin koroidal tipte olması ve yenidoğan döneminde tanı konulması nedenli olduğunu düşündük.

Yenidoğan döneminde tanı konulan GVA sıklıkla kalp yetmezliği ile beraber seyretmekte ve ek olarak gelişen pulmoner hipertansiyon da tedaviyi daha da karmaşık hale getirmektedir. Bu nedenle yenidoğan döneminde nedenini açıklayamadığımız PHT olan vakalarda, PHT tanısını koymadan önce mutlaka olası vasküler malformasyonlar açısından beyin ve karaciğer görüntülemesi yapılmalıdır. PHT'nun derecesi direkt olarak hemodinamik dengeyi etkilediğinden, tedavi zamanı ve prognoz üzerine önemli etkiye sahiptir (22). Literatürde GVA ile prezente olan vakaların hepsinde PHT saptanırken, PHT ağırlığı da prognozla ilişkili bulunmuştur. Bu nedenle vasküler direnci azaltmada duktal açıklığın sürdürülebildiği tedaviler kullanılması hastalığın tedavisinde fayda sağlayabilmektedir $(19,30)$. Çalışmamıza dahil edilen 5 hastadan 3'ünde (\%60) ağır pulmoner hipertansiyon saptandı. Ayrıca orta derecede pulmoner hipertansiyon kliniğine sahip iki hastamızın (\%40) kardiyak ve pulmoner açıdan ilaçsız takipleri devam etmekte olup literatür bilgileriyle uyumlu idi.

Tanı ve tedavi sürecinin erken yapıldığı, özellikle de kalp yetersizliğine yönelik desteğin erken dönemde başlanması ile sağkalımın arttığını gösteren çalışmalar çoğunluktadır $(14,17)$. GVA'da kalp yetmezliği tedavisinin medikal olarak kontrol altına alındığı ve ilk 1 yılda endovasküler cerrahi uygulanan hastalarda yaşam şansının arttı̆ı belirtilmiştir (27). Ancak endovasküler tedaviye karşın çocuklarda ve yenidoğanlarda ortalama mortalite sırasıyla \%9 ve \%50'dir. Ayrıca sağkalan vakalarda da morbiditeler görülmektedir. Özellikle nörolojik defisitler \%37-50 oranında görülmektedir. Ancak embolizasyon yapılan ve sağ kalan hastaların \%66'sında nörolojik bir sorun bulunmazken, \%14'ünde geçici nörolojik semptomlar, \%11.5'inde orta derecede nörolojik sorunlar, \%8.5'inde ise geri dönüşümsüz nörolojik hasar oluşarak nörolojik defisit gelişmektedir (33). Yine Rodesh ve ark. çalışmasında erken dönemde kalp yetmezliği tedavisi uygulanan ve 12 ay öncesinde cerrahi uygulanan hastalarda nörolojik sekel oranını \%33 olarak belirtmişlerdir (25). Vakalarımızdan erken dönemde kalp yetersizliği medikal olarak düzelen hastamızın (bebek 5) mevcut yaşı 34 ay olup nöromotor geriliği hafif düzeyde, cerrahi gereksinimi olan vakamız ise 20 aylık olup ağır nöromotor ve bilişsel gerilik mevcut idi ve sonuçlarımız literatür ile uyumlu idi.

Tedavi ile düzelmeyen PPHT'nun altta yatan nedenleri arasında GVA tanılar arasında mutlaka düşünülmelidir. Tedavi manevraları denenirken kraniyal USG ve sonrasında mutlaka kraniyal MRI ve MR anjiografi erken aşamada hemodinamik açıdan stabil olmayan bir hastada bile düşünülmelidir $(34,35)$. Özellikle postnatal dönemde primer kardiyak yapısal bozukluğu olmayan ve tedaviye dirençli PHT vakalarında arteriyovenöz fistüllerin, sıklıkla da GVA olasılığının değerlendirilmesi gerekmektedir. GVA‘na bağ।ı gelişen ciddi PHT ve kalp yetmezliklerinde süreç antenatal dönemde başladığından, antenatal dönemden itibaren bu hastaların tanısal ve takip işlemleri multidisipliner bir şekilde yürütülmelidir. Postnatal dönemde geri dönüşümsüz yetmezlik tablosu gelişmeden gerek kardiyak yetersizlik, gerekse de PHT tedavisi başlanması hastalık sürecinin daha iyi yönetilmesinde anahtar rol oynayacaktır. Erken başlanan tedavilere rağmen majör anomalisi olan ve organ disfonksiyonları engellenemeyen hastaların ise kaybedilmesi kaçınılmaz olacaktır.

\section{SONUÇ}

Erken dönemde mekanik ventilatör desteği ihtiyacı olan, medikal tedaviye rağmen düzelmeyen PHT olan yenidoğanlarda kardiyak yapısal patolojilerin dışlanmasıyla birlikte kraniyal görüntülemenin erken değerlendirilmesi ve şüpheli vakalarda GVA tanısının mutlaka akılda tutulması hayati öneme sahiptir.

Etik Komite Onayı: Bu çalışma için etik kurul onayı Giresun Üniversitesi Klinik Araştırmalar Etik Kurulu'ndan alınmıştı (06.02.2020/19).

Bilgilendirilmiş Onam: Katlımcılardan bilgilendirilmiş onam alınmıştır.

Hakem Değerlendirmesi: Dış bağımsız.

Yazar Katkıları: Çalışma Konsepti/Tasarım- M.B., D.K.A. ,K.Ç., E.T., A.B., Ö.E., A.B., S.B.Ö.; Veri Toplama- M.B., D.K.A., H.A.A., A.B., Ö.E.; Veri Analizi/Yorumlama- D.K.A., Ö.E., A.B., H.A.A., i.O.A.; Yazı Taslağı- M.B., D.K.A., K.Ç., E.T., S.B.Ö.; İçeriğin Eleştirel İncelemesi- M.B., D.K.A., E.T., S.B.Ö., I.O.A.; Son Onay ve Sorumluluk- M.B., D.K.A., K.Ç., E.T., Ö.E., H.A.A., A.B., I.O.A., S.B.Ö.

Çıkar Çatışması: Yazarlar çıkar çatışması beyan etmemişlerdir.

Finansal Destek: Yazarlar finansal destek beyan etmemişlerdir.

Ethics Committee Approval: This study was approved by Giresun University Clinical Research Ethics Committee (06.02.2020/19). 
Informed Consent: Written consent was obtained from the participants.

Peer Review: Externally peer-reviewed.

Author Contributions: Conception/Design of Study-- M.B., D.K.A., K.Ç., E.T., A.B., Ö.E., A.B., S.B.Ö..; Data Acquisition- M.B., D.K.A., H.A.A., A.B., Ö.E.; Data Analysis/Interpretation- D.K.A., Ö.E., A.B., H.A.A., I.O.A.; Drafting Manuscript- M.B., D.K.A., K.Ç., E.T., S.B.Ö.; Critical Revision of Manuscript- M.B., D.K.A., E.T., S.B.Ö., I.O.A.; Final Approval and Accountability- M.B., D.K.A., K.Ç., E.T., Ö.E., H.A.A., A.B., I.O.A., S.B.Ö.

Conflict of Interest: Authors declared no conflict of interest.

Financial Disclosure: Authors declared no financial support.

\section{KAYNAKLAR/REFERENCES}

1. Casasco A, Lylyk P, Hodes JE, Kohan G, Aymard A, Merland JJ. Percutaneous transvenous catheterization and embolization of vein of Galen aneurysms. Neurosurgery 1991;28:260-6.

2. Marques RM, Lobão CA, Sassaki VS, Aguiar LR. Vein of Galen aneurysm in an adult: case report. Arq Neuropsiquiatr 2006Sep;64(3B):862-4.

3. Lasjaunias P, Hui F, Zerah M, Garcia-Monaco R, Malherbe V, Rodesch G, et al. Cerebral arteriovenous malformations in children: management of 179 consecutive cases and review of the literature. Childs Nerv Syst 1995;11: 66-79.

4. Deloison B, Chalouhi GE, Sonigo P, Zerah M, Millischer AE, Dumez $Y$, et al. Hidden mortality of prenatally diagnosed vein of Galen aneurysmal malformation: retrospective study and review of the literature. Ultrasound Obstet Gynecol 2012;40:652-8.

5. Frawley GP, Dargaville PA, Mitchell PJ, Tress BM, Loughnan P. Clinical course and medical management of neonates with severe cardiac failure related to vein of Galen malformation. Arch Dis Child Fetal Neonatal Ed 2002;87:F144-F149.

6. Puthiyachirakkal M, Mhanna MJ. Pathophysiology, management, and outcome of persistent pulmonary hypertension of the newborn: a clinical review. Front Pediatr 2013;1:23.

7. Hilgendorff A, Apitz C, Bonnet D, Hansmann G. Pulmonary hypertension associated with acute or chronic lung diseases in the preterm and term neonate and infant. The European Paediatric Pulmonary Vascular Disease Network, end or sed by ISHLT and DGPK. Heart 2016;102(Suppl2):ii49-56.

8. Walsh-Sukys MC, Tyson JE, Wright LL, Bauer CR, Korones SB, Stevenson DK, et al. Persistent pulmonary hypertension of the newborn in the era before nitricoxide: practice variation and outcomes. Pediatrics 2000;105(1 Pt 1):14-20.

9. Lakshminrusimha S, Keszler M. Persistent Pulmonary Hypertension of the Newborn. Neoreviews 2015;16(12):680-92.

10. Weisz DE MP. Cardiovascular Assessment. In: Goldsmith J KE, Suresh G, Keszler M. editors. Assisted Ventilation of the Neonate. Sixth ed. Philadelphia: Elsevier; 2017.

11. Bendapudi P, Rao GG, Greenough A. Diagnosis and management of persistent pulmonary hypertension of the newborn. Paediatr Respir Rev 2015;16(3):157-61.

12. Garcia-Monaco R, De Victor D, Mann C, Hannedouche A, Terbrugge K, Lasjaunias P. Congestive cardiac manifestations from cerebrocranial arteriovenous shunts: endovascular management in 30 children. Childs Nerv Syst 1991;7:48-52.
13. Su W, Hsieh W, Chou H, Peng S, Yao Y, Won S, et al. Persistent pulmonary hypertension in a neonate with vein of Galen arteriovenous malformation. J Formos Medical Association 2005;104(9):670-3.

14. Dahdah N, Alesseh H, Dahms B, Saker F. Severe pulmonary hypertensive vascular disease in two newborns with aneurysmal vein of Galen. Pedatric Cardiology 2001;22:538-41. doi: 10.1007/ s002460010294.

15. D'Alto M, Romeo E, Argiento P, Di Salvo G, Badagliacca R, Cirillo $A P$, et al. Pulmonary arterial hypertension: the key role of echocardiography. Echocardiography. 2015;32 Suppl 1:S23-37.

16. Bendapudi P, Rao GG, Greenough A. Diagnosis and management of persistent pulmonary hypertension of the newborn. Paediatr Respir Rev 2015;16(3):157-61.

17. Raybaud CA, Strother CM, Hald JK. Aneurysms of the vein of Galen: embryonic considerations and anatomical features relating to the pathogenesis of the malformation. Neuroradiology 1989;31:109-28.

18. Jones BV, Bal WS, Tomsick TA, Millard J, Crone KR. Vein of Galen aneurysmal malformation: diagnosis and treatment of 13 children with extended clinical follow-up. AJNR 2002;23:1717-24.

19. Chevret L, Durand P, Alvarez H, Lambert V, Caeymax L, Rodesch $G$, et al. Severe cardiac failure in newborns with VGAM. Prognosis significance of hemodynamic parameters in neonates presenting with severe heart failure owing to vein of Galen arteriovenous malformation. Intensive Care Med 2002;28:1126-30.

20. Golombek SG, Ally S, Woolf P K. A newborn with cardiac failure secondary to a large vein of Galen malformation. South Med J 2004;97:516-8.

21. Mitchell PJ, Rosenfeld JV, Dargaville P, Loughnan P, Ditchfield MR, Frawley G, et al. Endovascular management of vein of Galen aneurysmal malformation spresenting in the neonatal period. AJNR Am J Neuroradiol 2001;22:1403-9.

22. Lasjaunias PL, Chng SM, Sachet M, Alvarez H, Rodesch G, GarciaMonaco R. The management of vein of Galen aneurysmal malformations. Neurosurgery 2006;59:184-94.

23. Jones BV, Ball WS, Tomsick TA, Millard J, Crone KR. Vein of Galen aneurysmal malformation: diagnosis and treatment of 13 children with extended clinical follow-up. AJNR 2002.23.1717-24.

24. Osborn AG. Intracranial vascular malformations. In: Diagnostic Neuroradiology Mosby, 1994.p284-329.

25. Rodesch G, Hui F, Alvarez H, Tanaka A, Lasjaunias P: Prognosis of antenatally diagnosed vein of Galen aneurysmal malformations. Childs Nerv Syst 1994;10:79-83.

26. Saliou G, Vraka I, Teglas JP, Senat MV, Durand P, Colmant C, et al. Pseudofeeders on fetal magnetic resonance imaging predict outcome in vein of Galen malformations. Ann Neurol 2017;81(2):278-86.

27. Tiwary S, Geethanath RM, Abu-Harb M. Vein of Galen malformation presenting as persistent pulmonary hypertension of newborn. BMJ Case Reports 2013;2013.

28. Mathews AZ, Ibhanesebhor S, Richens T, Manjunatha CM. Heart failure in the newborn; vein of Galen aneurysmal malformation. BMJ Case Reports 2013;2013.

29. Bozkaya D, Çelik HT, Arat A, Yiğit Ş, Yurdakök M. Yenidoğan Döneminde Kalp Yetmezliği Bulguları ile Seyreden Arterio-Venöz Malformasyon; Galen Ven Anevrizması. Jinekoloji-Obstetrik ve Neonatoloji Tıp Derg 2018;15(3):120-4. 
30. Mortazavi MM, Griessenauer CJ, Foreman P, Reza BS, Mohammadali MS, Curtis JR, et al. Vein of Galen aneurysmal malformations: critical analysis of the literature with proposal of a new classification system. J Neurosurg Pediatr 2013;12(3):293306.

31. Fullerton HJ, Aminoff AR, Ferriero DM, Gupta N, Dowd CF. Neurodevelopmental outcome after endovascular treatment of vein of Galen malformations. Neurology 2003;61:1386-90.

32. Geibprasert S, Krings T, Armstrong D, Terbrugge KG, Raybaud CA. Predicting factors for the follow-up outcome and management decisions in vein of Galen aneurysmal malformations. Childs Nerv Syst 2010;26:35-46.
33. Ashida Y, Miyahara H, Sawada H, Mitani Y, Maruyama K. Anesthetic management of a neonate with vein of Galen aneurismal malformations and severe pulmonary hypertension. Pediatr Anaesth 2005;15:525-8.

34. Erdoğan İ, Uluğ MH, Çizmeli MO. Galen veni anevrizmalarının tedavisinde yeni bir seçenek: transtorküler embolizasyon. Türk Nöroşirurji Dergisi 1989;1:25-30.

35. Tekşam Ö, Çekirge S, Yiğit Ş, Karagöz T, Yurdakök M. Bir yenidoğanda ağır kalp yetmezliğine neden olan Galen ven anevrizmasının transumblikal yolla embolizasyonu. Çocuk Sağlığı ve Hastalıkları Dergisi 2005;48:168-74. 